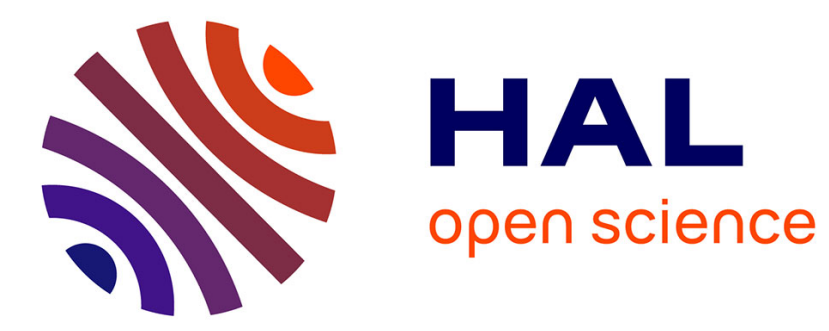

\title{
Influence of work function on the multipactor threshold
}

\author{
Adrien Plaçais, Eden Sorolla, Mohamed Belhaj, Julien Hillairet, Jérôme Puech
}

\section{To cite this version:}

Adrien Plaçais, Eden Sorolla, Mohamed Belhaj, Julien Hillairet, Jérôme Puech. Influence of work function on the multipactor threshold. 2018 IEEE MTT-S International Conference on Numerical Electromagnetic and Multiphysics Modeling and Optimization, NEMO 2018, Aug 2018, REYKJAVIK, Iceland. hal-02262204

\section{HAL Id: hal-02262204 https://hal.science/hal-02262204}

Submitted on 2 Aug 2019

HAL is a multi-disciplinary open access archive for the deposit and dissemination of scientific research documents, whether they are published or not. The documents may come from teaching and research institutions in France or abroad, or from public or private research centers.
L'archive ouverte pluridisciplinaire HAL, est destinée au dépôt et à la diffusion de documents scientifiques de niveau recherche, publiés ou non, émanant des établissements d'enseignement et de recherche français ou étrangers, des laboratoires publics ou privés. 


\title{
Influence of work function on the multipactor threshold
}

\author{
Adrien Plaçais*†‡, Edén Sorolla ${ }^{\ddagger \S}$, Mohamed Belhaj*, Julien Hillairet ${ }^{\dagger}$ and Jérôme Puech ${ }^{\ddagger}$ \\ ${ }^{*}$ DPHY, ONERA, Université de Toulouse F-31055 Toulouse, France \\ ${ }^{\dagger}$ CEA, IRFM, F-13108 Saint-Paul-Lez-Durance, France \\ ${ }^{\ddagger} \mathrm{CNES}, \mathrm{DSO} / \mathrm{RF} / \mathrm{HNO}, \mathrm{F}-31401$ Toulouse, France \\ $\S$ XLIM - UMR 7252, Université de Limoges/CNRS F-87060 Limoges, France
}

\begin{abstract}
The multipactor effect is characterized by a very fast growth of the electronic population in vacuum Radio-Frequency (RF) devices. As it limits the transmitted RF power and can severely damage RF systems, multipactor has been subject to an extensive research for the past decades. Simulation tools are relatively accurate for the simplest cases, but less reliable for advanced problems: presence of an external magnetic field, complex geometry, time or temperature-dependent materials properties, etc. A code simulating the multipactor within an infinite parallelplate waveguide with a dielectric coating on the bottom plate has been developed. The inclusion of a realistic energy distribution for the secondary electrons and a new emission model shows a strong dependence of the multipactor threshold on the metal work function and on the dielectric electric charge.
\end{abstract}

\section{INTRODUCTION}

The multipactor effect is an electronic avalanche that can occur in radio-frequency (RF) devices under vacuum when the electron motion fulfills a resonance condition with the RF electric field above a certain field threshold $E_{\max }$. Such phenomenon may appear in telecommunications satellites [1], but also in RF plasma heating systems in experimental fusion reactors (tokamaks) [2]. The generated electron cloud may disturb the transmitted signal or reflect it back to the source; in the worst cases it can trigger a breakdown, leading to a very high increase in temperature that may affect the device's materials or provoke outgassing processes and corona discharges.

When an electron beam impacts on a dielectric sample, an electron flux comes out, which is composed of backscattered and true secondary electrons [3]. The former are primary electrons returning to the vacuum, and the latter are valence electrons removed from the material. We define the Total Electron Emission Yield (TEEY) as the number of backscattered and secondary electrons over the number of primary electrons and it must be larger than unity for the electron cloud to develop. The TEEY is highly dependent on the energy and incidence angle of the primary flux [4], the nature and surface condition of the sample [5], the presence of a magnetic field [6]... External magnetic or electric field will also modify the particle trajectories, influencing the RF/electron resonance and thus making the multipactor phenomenon more complex [7]. In tokamaks, RF antennas are used to heat or drive current in fusion plasma, and are subject to a magnetic field so that to ensure the plasma confinement. In satellite circulators, isola- tors containing ferrite materials are used to guide the signal from the source to the transmit antenna, while preventing the power reflection towards the source.

Dielectrics are of particular interest for the latter systems. They are used in space applications to reduce the dimensions of RF components or inside circulators like the ferrites. In tokamaks, dielectric windows are used to ensure the sealing between vacuum vessel and pressurized transmission lines. Unlike metals, dielectric can hold a net electric charge, creating an additional DC electric field. This charge varies with time, and its origin relies on all previous interactions with electrons. Furthermore, their TEEY is linked to the sign and magnitude of the charge [8]: if a dielectric's TEEY is lower than unity, a net negative charge is injected in the sample. This charge gives rise to an electric field in the vacuum, which slows down the incident electrons and shifts their impact velocity to lower values. The resulting decrease in electron impact energy eventually leads to a TEEY equals to unity, when all primaries are reflected by the dielectric electric field [9]. Conversely, if the TEEY is higher than unity, the dielectric charges positively and primary electrons will be accelerated by some $\mathrm{eV} \mathrm{[10].} \mathrm{In} \mathrm{addition} \mathrm{to} \mathrm{these} \mathrm{external} \mathrm{effects} \mathrm{of} \mathrm{charging,}$ the internal effect may also lead to substantial change on the TEEY curves by interfering with the transport of secondaries undergoing emission [8].

As multipactor tests can be destructive, measuring the $E_{\max }$ is expensive. Therefore creating numerical multipactor prediction tools is valuable. Most of them [11]-[13] are effective for the simplest cases, with only an RF field in a rectangular waveguide of pure metal, though they can only highlight trends once the problem becomes more complex.

Current multipactor mitigation techniques consist of modifying the component geometry or some treatment to the materials surface [14]. Another promising method consists of applying a DC magnetic field to the system [15]. This paper numerically demonstrates the importance of the materials work function in waveguides, what could facilitate the development of new surface treatment processes for multipactor mitigation, as it is known that oxidation, contamination and the deposition of ultrathin films on metals could modify their work function [10]. 


\section{Methodology}

Several models have been developed to study the effect that a dielectric material of a waveguide has on the multipactor [16]-[18]. However, none of them took into account the effect of the electric charge on the Secondary Electron Yield (SEY), which is just the ratio of secondary to primary electrons. This need was filled by Sorolla et al. [19] who developed a code simulating an infinite metal-metal parallel-plate geometry of gap $d$, represented Fig. 1, with a dielectric slab of thickness $h$ covering the bottom plate (II).

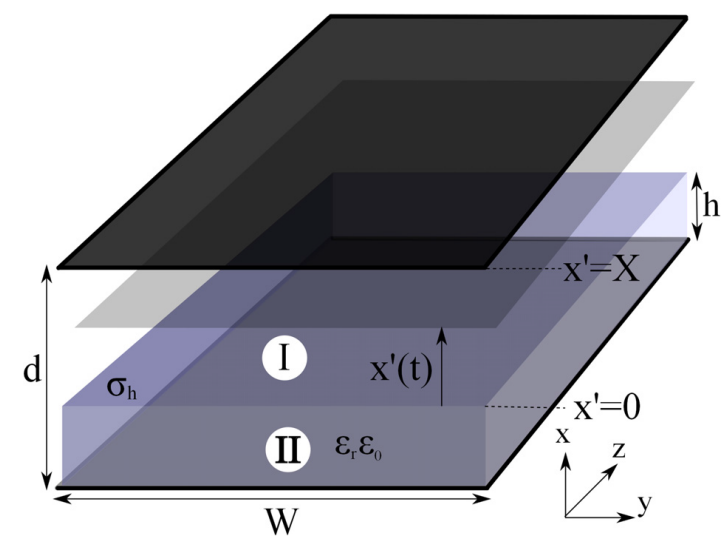

Fig. 1. Sketch of the parallel-plate waveguide with a dielectric slab [19]

The model considers a very thin sheet of electrons located at $x^{\prime}(t)$ moving between the metal plate and the dielectric slab. The electron sheet position can be calculated analytically or using Runge-Kuta or Bulirsch-Stoer schemes [20]. The RF magnetic field is neglected, so the problem is 1D. Each time a collision occurs, the SEY $\delta$ is calculated according to the Dionne model [21], with a slight modification [10] for the metal in order to obtain the SEY dependence on its work function:

$$
\delta\left(E_{i}, W_{f}\right)=\delta\left(E_{i}, W_{f}^{0}\right) \cdot\left(\frac{W_{f}}{W_{f}^{0}}\right)^{-3}
$$

$W_{f}^{0}$ is the unaltered pure metal work function, on which secondary emission properties have been measured, and $W_{f}$ is the actual metal work function. This modifications introduce a dependency of the multipactor threshold on $W_{f}$, which is the energy that electrons need to be provided so as to escape the material. If the dielectric is involved, the SEY is modified according to its charge [8], [19] and the created electric field, $E_{\mathrm{d}}$, is updated. The electron sheet is finally re-emitted with an energy $E_{\text {sec }}$. The Backscattered Electron Yield $\eta$ is a constant and elastic and inelastic backscattered electrons are not separated from secondary electrons. If a given electron density limit is reached before the time limit, the simulation stops; otherwise, $E_{\mathrm{RF}}$ is increased and the simulation starts again until a multipactor threshold $E_{\max }$ is found. It is possible to perform a sweep over the initial dielectric surface holes density $\sigma_{h, 0}$. It can be positive (excess of holes) or negative (excess of electrons).
The second novelty of this work lies in the inclusion of an energy distribution for the emitted electrons. The previous version of the code used a mono-energetic emission model which is a limiting scenario. The Chung and Everhart distribution [22] is used here, all energies being defined prior to the vacuum level:

$$
f\left(E_{\text {sec }}\right)=\frac{E_{\text {sec }}}{\left(E_{\text {sec }}+\Phi\right)^{4}}
$$

$\Phi$ is the effective work function. For a metal, $\Phi=W_{f}$, and for a dielectric, $\Phi=\chi+E_{g}$ where $\chi$ is the electron affinity and $E_{g}$ the gap energy.

\section{RESUlts}

The same simulation parameters as in Sorolla et al. [19] are used here, with an inter-plate distance $d=10 \mathrm{~mm}$ and a dielectric slab of thickness $h=9.9 \mathrm{~mm}$. The electron sheet position is calculated analytically. The dielectric is Teflon (PTFE), with emission data extracted from [23], an electrical permittivity $\epsilon_{r}=2.4, \chi=1.1 \mathrm{eV}$ and $E_{g}=7.7 \mathrm{eV}$ [24]. The metal is silver, with emission data measured at the ONERA [25] and with $W_{f}^{\mathrm{Ag}}=4.23 \mathrm{eV}$ [26]. A second study has been led, considering a unique layer of perfluorinated alkanethiol (PA) deposited onto the silver. In this configuration, $W_{f}^{\mathrm{PA} / \mathrm{Ag}}=5.8 \mathrm{eV}$ [27]. Figures 2 and 3 represent the secondary electron population distribution and the TEEY of the two materials, respectively, both as a function of the incident electron energy. We considered that the multipactor threshold was reached when the electrons surface density between the plates raised up to $\sigma_{f}=10^{6} \mathrm{~m}^{-2}$. The working frequency is $f=11.3 \mathrm{GHz}$. The results have been obtained by averaging the multipactor threshold obtained for ten identical simulations. They were removed if the multipactor did not appear at least five times. The influence of the effective work function of the dielectric will not be discussed here, even if it leads to similar results.
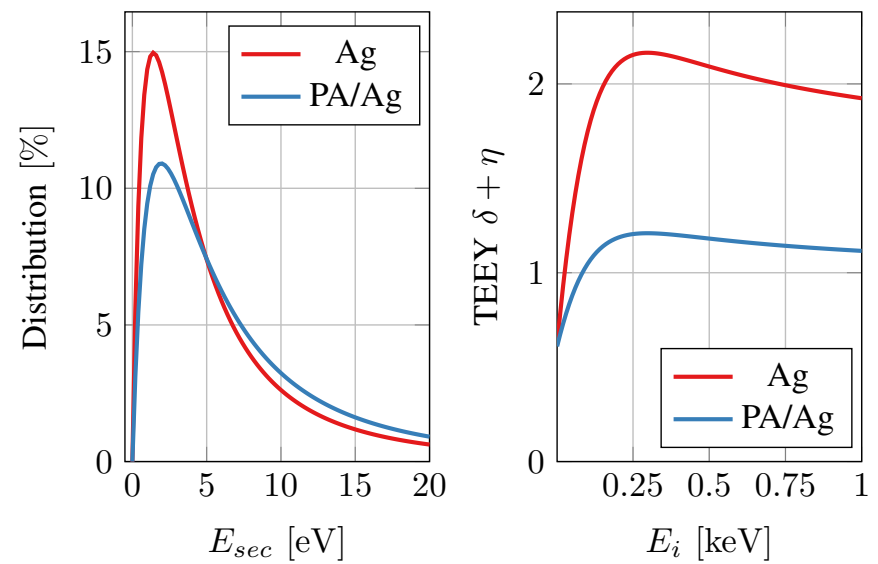

Fig. 2. Energy distribution normalized over $[0,+\infty[$

Fig. 3. TEEY as a function of the incident electron energy

Fig. 4 shows the calculated multipactor threshold as a function of the initial holes density on the Teflon slab. The 
coated and the uncoated silver present the same shape, both positive and negative initial charging of the dielectric resulting in a threshold increase. At a given value of initial surface density, the threshold is higher for negative charges (i.e. $\sigma_{h, 0}<0$ ), which is different from E. Sorolla et al. results [19].

The addition of the PA layer induced a raising of the multipactor threshold $E_{\max }$ between $40 \%$ and $60 \%$. A multipactor threshold was then found for $\sigma_{h, 0} \in$ $\left[-0.7 \cdot 10^{13} \mathrm{~m}^{-2} ; 0.7 \cdot 10^{13} \mathrm{~m}^{-2}\right]$.

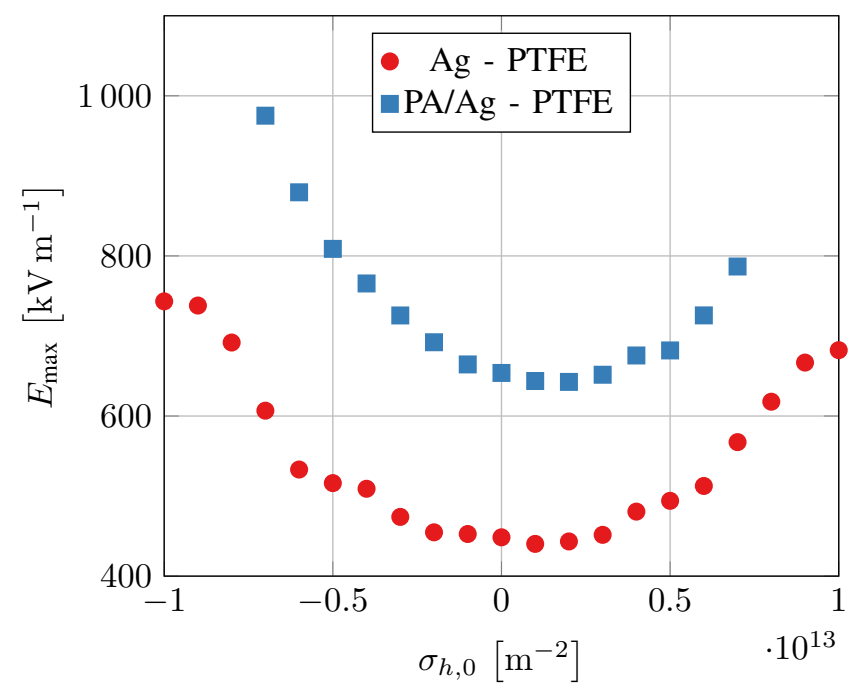

Fig. 4. Variation of the multipactor threshold with the initial surface density of holes on the Teflon slab

\section{DISCUSSION}

We can see in Fig. 4 that an augmentation in surface density $\left|\sigma_{h, 0}\right|$ leads to an augmentation in $E_{\max }$. When the dielectric presents an excess of holes (i.e., $\sigma_{h}>0$ ), the electron sheet is slowed down when moving from the slab to the metal. Hence, the SEY on the metal is inferior to unity and the multipactor cannot develop. Similarly, if the dielectric presents an excess of electrons, the sheet is repelled from the slab, leading to a low SEY on the dielectric. In both cases, the increase in SEY of a plate does not compensate the decrease in SEY of the other plate. Indeed, the slowest electrons emitted by the lowSEY plate cannot even reach the high-SEY plate, the dielectric electric field acting as a high-pass filter. It is thus more accurate to use an energy distribution for the secondaries and to calculate an average over multiple runs rather than to use a mono-energetic model. Although one-surface multipactor dynamics exists [28], it does not seem to be predominant here.

In Sorolla et al. paper [19], the electron cloud necessitated a lower electric field to develop if $\sigma_{h, 0}<0$, which is different from our results (Fig. 4). As a matter of fact, we used for our simulations a more emissive silver, that requires the same incident energy as the slab to emit electrons. As the Teflon's SEY is slightly inferior to the metal's, the multipactor threshold is higher when $\sigma_{h, 0}<0$, when the electron sheet is repelled from the Teflon slab and its SEY is critical.
As we can see on Fig. 3, the increase in work function due to the coating induces a tremendous SEY reduction. As most of secondary electrons are emitted at energies scaling from some $\mathrm{eV}$ to a few tens of $\mathrm{eV}$, a small work function increment will prevent a great number of secondaries from being emitted in the vacuum. N. Fil et al. showed that the first cross-over energy $E_{c, 1}$, defined as the first incident electron energy for which $\delta=1$, was of major importance in the multipactor apparition [29]. As the coating induced a raise in $E_{c, 1}$ from $26 \mathrm{eV}$ to $84 \mathrm{eV}$, a greater electric field is required to accelerate electrons above this threshold, $\delta+\eta>1$ being a necessary condition for the multipactor formation.

When the SEY of the metal is reduced, the Teflon slab becomes more important as an electron source. If $\left|\sigma_{h, 0}\right|$ is increased, one of the plates will see a decrease of its SEY. In order to overcome the dielectric electric field $E_{\mathrm{d}}, E_{\max }$ has to be increased. This can however be detrimental to the SEY of the other plate, as after a given incident electron energy the SEY is diminishing. Thus, the multipactor can disappear for extreme values of $\left|\sigma_{h, 0}\right|$. Consequently, the increase in RF field leads to a very wide SEY spread, so it is primordial to perform several simulations. This multipactor disappearance is not observed with a monoenergetic model.

\section{CONCLUSions}

The improvement of a multipactor code highlighted the influence of the waveguides' materials work function on $E_{\max }$. Even if all mechanisms are not yet fully understood and the model is still incomplete, this work paves the way to new multipactor mitigation processes and to a better understanding of relations between aging processes and $E_{\max }$ alteration. The inclusion of a non monoenergetic model for the secondaries showed a disappearance of the multipactor for the coated silver at extreme values of $\left|\sigma_{h, 0}\right|$. However, it appears that Henke et al. model [30] could favorably replace the Chung and Everhart distribution for the dielectric slab [10]. Also, the treatment of backscattered electrons is to be improved, as their energy distribution is different from the secondaries and as $\eta$ is not a constant.

\section{REFERENCES}

[1] J. de Lara, F. Perez, M. Alfonseca, L. Galan, I. Montero, E. Roman, and D. Garcia-Baquero, "Multipactor prediction for on-board spacecraft RF equipment with the MEST software tool," IEEE Trans. Plasma Sci., vol. 34, no. 2, pp. 476-484, apr 2006. [Online]. Available: https://doi.org/10.1109/TPS.2006.872450

[2] M. Goniche, C. El Mhari, M. Francisquez, S. Anza, J. Belo, P. Hertout, and J. Hillairet, "Modelling of power limit in RF antenna waveguides operated in the lower hybrid range of frequency," Nucl. Fusion, vol. 54, no. 1, p. 013003, jan 2014. [Online]. Available: https://doi.org/10.1088/0029-5515/54/1/013003

[3] K. Kanaya and H. Kawakatsu, "Secondary electron emission due to primary and backscattered electrons," J. Phys. D. Appl. Phys., vol. 5, no. 9, p. 330, sep 1972. [Online]. Available: https://doi.org/10.1088/0022-3727/5/9/330

[4] A. Dekker, "Secondary Electron Emission," in Solid State Phys. 1958, vol. Volume 6, pp. 251-311. [Online]. Available: https: //doi.org/10.1016/S0081-1947(08)60728-6 
[5] T. Gineste, M. Belhaj, G. Teyssedre, and J. Puech, "Investigation of the electron emission properties of silver: From exposed to ambient atmosphere Ag surface to ion-cleaned Ag surface," Appl. Surf. Sci., vol. 359, pp. 398-404, dec 2015. [Online]. Available: https://doi.org/10.1016/j.apsusc.2015.10.121

[6] N. Fil, M. Belhaj, J. Hillairet, J. Puech, and R. Mathevet, "Electron emission under uniform magnetic field of materials for fusion and space applications," Fusion Eng. Des., no. 1, 2017. [Online]. Available: https://doi.org/10.1016/j.fusengdes.2017.03.039

[7] N. K. Vdovicheva, A. G. Sazontov, and V. A. Sazontov, "Influence of an external magnetic field on the threshold of multipactor onset on a dielectric surface," Radiophys. Quantum Electron. vol. 50, no. 2, pp. 108-122, 2007. [Online]. Available: https: //doi.org/10.1007/s11141-007-0010-3

[8] M. Belhaj, T. Tondu, and V. Inguimbert, "Effect of the incident electron fluence on the electron emission yield of polycrystalline Al2O3," Appl. Surf. Sci., vol. 257, no. 10, pp. 4593-4596, mar 2011. [Online]. Available: http://doi.org/10.1016/j.apsusc.2010.12.081

[9] M. Belhaj, D. Payan, and J. Puech, "About the electron emission properties of dielectric materials," in MULCOPIM, no. 1, Noordwijk, The Netherlands, 2017.

[10] J. Cazaux, "Calculated influence of work function on SE escape probability and Secondary Electron Emission yield," Appl. Surf. Sci., vol. 257, no. 3, pp. 1002-1009, nov 2010. [Online]. Available: http://doi.org/10.1016/j.apsusc.2010.08.007

[11] CST, "Multipacting in Waveguide Components and Cavities," 2012.

[12] M. Francisquez, "Power Limit Modeling of Lower Hybrid Antenna Waveguides in Tokamaks," Bachelor of Arts Honors Thesis, Dartmouth College (Hanover, NH), 2012.

[13] Aurorasat, "SPARK3D User Manual," 2015.

[14] R. L. Geng, H. Padamsee, S. Belomestnykh, P. Goudket, D. M. Dykes, and R. G. Carter, "Suppression of multipacting in rectangular coupler waveguides," Nucl. Instruments Methods Phys. Res. Sect. A Accel. Spectrometers, Detect. Assoc. Equip., vol. 508, no. 3, pp. 227-238, 2003. [Online]. Available: https://doi.org/10.1016/S0168-9002(03)01660-7

[15] S. Anza Hormigo, J. Vague, B. Gimeno, V. E. Boria, D. Raboso, C. P. Vicente, and J. Gil, "Multipactor mitigation in coaxial technology by means of the use of static magnetic fields : recent experiments and simulations," in MULCOPIM, no. 1, Valencia, Spain, 2014.

[16] R. Kishek, Y. Y. Lau, L. K. Ang, A. Valfells, and R. M. Gilgenbach, "Multipactor discharge on metals and dielectrics: Historical review and recent theories," Phys. Plasmas, vol. 5, no. 5, pp. 2120-2126, may 1998. [Online]. Available: https://doi.org/10.1063/1.872883

[17] G. Torregrosa, Á. Coves, C. P. Vicente, A. M. Pérez, B. Gimeno, and V. E. Boria, "Time evolution of an electron discharge in a parallel-plate dielectric-loaded waveguide," IEEE Electron Device Lett., vol. 27, no. 7, pp. 619-621, 2006. [Online]. Available: https://doi.org/10.1109/LED.2006.877284
[18] A. Coves, G. Torregrosa, C. P. Vicente, B. Gimeno, and V. Boria "Multipactor Discharges in Parallel-Plate Dielectric-Loaded Waveguides Including Space-Charge Effects," IEEE Trans. Electron Devices, vol. 55, no. 9, pp. 2505-2511, sep 2008. [Online]. Available: https://doi.org/10.1109/TED.2008.927945

[19] E. Sorolla, M. Belhaj, J. Sombrin, and J. Puech, "New multipactor dynamics in presence of dielectrics," Phys. Plasmas, vol. 24, no. 10, p. 103508, oct 2017. [Online]. Available: https://doi.org/10.1063/1. 5001832

[20] W. H. Press, S. A. Teukolsky, W. T. Vetterling, and B. P. Flannery, Numerical Recipes in Fortran 77. The Art of Scientific Computing (Second Edition). Cambridge University Press, 1992. [Online]. Available: http://apps.nrbook.com/fortran/index.html

[21] G. F. Dionne, "Effects of secondary electron scattering on secondary emission yield curves," J. Appl. Phys., vol. 44, no. 12, pp. 5361-5364, dec 1973. [Online]. Available: https://doi.org/10.1063/1.1662156

[22] M. S. Chung and T. E. Everhart, "Simple calculation of energy distribution of low-energy secondary electrons emitted from metals under electron bombardment," J. Appl. Phys., vol. 45, no. 2, pp. 707709, feb 1974. [Online]. Available: https://doi.org/10.1063/1.1663306

[23] N. Balcon, M. Belhaj, T. Tondu, J. C. Mateo-Velez, and D. Payan, "Secondary electron emission of cover glasses: Temperature and incident flux effects," in Int. Symp. Mater. Sp. Environ., L. Ouwehand, Ed. Noordwijk, The Netherlands: ESA Communications, 2013.

[24] D. Tan and P. Irwi, "Polymer Based Nanodielectric Composites," in Adv. Ceram. - Electr. Magn. Ceram. Bioceram. Ceram. Environ. InTech, sep 2011, ch. 7, p. 122. [Online]. Available: https://doi.org/10.5772/23012

[25] M. Belhaj and T. Gineste, "ONERA silver TEEY measurements," 2016 [Online]. Available: https://doi.org/10.5281/zenodo.154266

[26] S. Prada, U. Martinez, and G. Pacchioni, "Work function changes induced by deposition of ultrathin dielectric films on metals: A theoretical analysis," Phys. Rev. B, vol. 78, no. 23, p. 235423, dec 2008. [Online]. Available: https://doi.org/10.1103/PhysRevB.78.235423

[27] B. de Boer, A. Hadipour, M. M. Mandoc, T. van Woudenbergh, and P. W. M. Blom, “Tuning of Metal Work Functions with Self-Assembled Monolayers," Adv. Mater., vol. 17, no. 5, pp. 621-625, mar 2005. [Online]. Available: https://doi.org/10.1002/adma.200401216

[28] W. Schrader, "A new mode of cyclotron resonance multipacting," Physica, vol. 40, no. 2, pp. 223-228, dec 1968. [Online]. Available: https://doi.org/10.1016/0031-8914(68)90020-7

[29] N. Fil, M. Belhaj, J. Hillairet, and J. Puech, "Multipactor threshold sensitivity to total electron emission yield in small gap waveguide structure and TEEY models accuracy," Phys. Plasmas, vol. 23, no. 12, p. 123118, dec 2016. [Online]. Available: https://doi.org/10.1063/1. 4972571

[30] B. L. Henke, J. Liesegang, and S. D. Smith, "Soft-x-ray-induced secondary-electron emission from semiconductors and insulators: Models and measurements," Phys. Rev. B, vol. 19, no. 6, pp. 3004 3021, mar 1979. [Online]. Available: https://doi.org/10.1103/PhysRevB. 19.3004 